\title{
A Hallmark of Progressive Diagnosis: Robinow Syndrome Identified By Clinical and Radiological Examination
}

\author{
Authors \\ Iraj Alam Khan ${ }^{1}$, Uzma Firdaus ${ }^{2}$, Syed Manazir $\mathrm{Ali}^{3}$ \\ ${ }^{1}$ Senior Resident, Dept of Pediatrics, J.N.Medical College, A. M. U. Aligarh, Uttar Pradesh, India, \\ Email: khan_iraj8f@yahoo.co.in \\ ${ }^{2}$ Assistant Professor, Dept of Pediatrics, J.N.Medical College, A. M. U. Aligarh, Uttar Pradesh, India, \\ Email:druzmafirdaus@gmail.com \\ ${ }^{3}$ Professor, Dept of Pediatrics, J.N.Medical College, A. M. U. Aligarh, Uttar Pradesh, India, \\ Email:manazir1958@yahoo.com \\ Corresponding Author \\ Iraj Alam Khan \\ Dept of Pediatrics, J.N.Medical College, A. M. U. Aligarh, Uttar Pradesh, India \\ Email: khan_iraj8f@yahoo.co.in \\ Address c/o Ashraf Sardar, Taleem Manzil, Marris Road, Aligarh, Uttar Pradesh, India, 202001

\begin{abstract}
Robinow syndrome also known as 'fetal facies' is a rare inherited disorder characterized by short stature due to mesomelic shortening of limbs, distinctive craniofacial, skeletal and genital abnormalities. It can have both autosomal recessive and autosomal dominant inheritance. The diagnosis depends on good clinical examination and radiological study. Prenatal diagnosis of Robinow syndrome can be made through fetal ultrasound examination. The treatment involves surgery, orthotics and hormone replacement and the prognosis remains reasonably good. Here we present a preterm newborn with typical dysmorphic facies and other congenital abnormalities characteristic of Robinow syndrome.

Keywords: Robinow syndrome, fetal facies, mesomelic limb shortening, hemivertebrae, genital hypoplasia
\end{abstract}

\section{Introduction}

Robinow syndrome is a rare inherited disorder characterized by short stature, distinctive craniofacial abnormalities, skeletal malformations and genital abnormalities ${ }^{1}$. Both autosomal recessive and autosomal dominant inheritance patterns are described. Typical clinical features and radiological findings are usually sufficient for establishing the diagnosis. Here we describe a newborn with typical dysmorphic facies and other congenital abnormalities characteristic of
Robinow syndrome. The mechanism of causation and brief outline of management and prevention are also presented.

\section{Case Report}

A 33 week preterm male baby was delivered by caesarean section (indication fetal distress) to a 29 year old second gravida mother. There was a history of previous still birth (apparently unknown cause). The baby was born of non consanguineous marriage and weighed $1.380 \mathrm{~kg}$ (below $10^{\text {th }}$ 
percentile), had a length of $37 \mathrm{~cm}$ (between $3^{\text {rd }}$ and $10^{\text {th }}$ percentile for gestation) and head circumference of $31 \mathrm{~cm}$ (above $50^{\text {th }}$ percentile). On physical examination, the baby was found to have mesomelic shortening of limbs and notable micropenis. Facial features were prominent with ocular hypertelorism, upturned nose with anteverted nostrils and depressed nasal bridge. Initially baby had respiratory distress for which supportive management was initiated and the baby responded favourably. The skeletelogram showed mesomelic shortening of bones, multiple segmentation anomalies in thoracic vertebrae and bifid fifth rib. According to typical morphological features and skiagram abnormalities, the diagnosis of Robinow syndrome was made.

\section{Discussion}

In 1969, Robinow et $a l^{2}$ described a rare form of dwarfism associated with mesomelic limb shortening, hemivertebrae and genital hypoplasia. Robinow proposed the term "fetal facies" to describe the characteristic facial appearance that continues to be used even today. The incidence is 1 in 5,00,000 with no sex predeliction ${ }^{3}$. Robinow syndrome can be inherited in both an autosomal dominant and autosomal recessive manner, autosomal recessive type being the more severe form. In the autosomal dominant type, the child inherits a single mutated or altered gene from one parent, however the offender gene remains largely unknown. A mutation in the ROR2 gene (located on chromosome 9) ${ }^{4}$ causes the autosomal recessive variety. The ROR2 protein plays a critical role in the formation of the skeleton, heart, and genitals. Mutations in the ROR2 gene hamper the synthesis of functional ROR2 protein, which in turn disrupts embryonic development and leads to the characteristic features of Robinow syndrome. $^{5,6}$

The facial features of infants with Robinow syndrome resemble those of an eight-week-old fetus; thus the name "fetal face" ${ }^{\text {.7 }}$ Characteristic craniofacial features may include a plethora of malformations such as macrocephaly, frontal bossing, ocular hypertelorism, anteverted nose, sunken (depressed) nasal bridge, gum hypertrophy, inverted lip with $\mathrm{V}$ appearance and low set ears with deformed pinna ${ }^{8}$.

Skeletal malformations may include forearm bones that are unusually short (forearm brachymelia), abnormally short fingers and toes, permanent fixation of the fifth fingers in a bent position (clinodactyly), unusually small hands with broad thumbs, malformation of the ribs, scoliosis and hemivertebrae ${ }^{8}$.Genital abnormalities are characterized by micropenis, cryptorchidism in affected males and hypoplasia of the clitoris and underdeveloped labia majora in affected females. Approximately $10-20 \%$ percent of infants with Robinow syndrome have congenital heart defects ${ }^{9}$, the most common being right ventricular outlet obstruction. Some of these are serious enough to warrant regular review by a cardiologist and timely surgical intervention. Our baby did not show any abnormality on echocardiography.

Prenatal diagnosis of Robinow Syndrome can be made through fetal ultrasound examination. The ulnar length to humeral length ratio is especially useful in prenatal diagnosis. ${ }^{10}$ Children diagnosed with Robinow Syndrome may require extensive surgical care for skeletal abnormalities. Additionally, orthotics or braces may be needed to help with walking and to stabilize the arms and legs. Orthodontic care may be needed if the teeth are crowded together. In a few cases, facial reconstructive surgery may be needed. Boys may have low testosterone levels, which causes poor growth and underdevelopment of the genitalia. Hormone therapy with testosterone and/or human chorionic gonadotropin will help increase growth. For both boys and girls, therapy with recombinant human growth hormone has been shown to increase growth rates.

This disease need to be differentiated from Aarskorg syndrome which shows peculiar type of scrotal syndrome (saddle scrotum) and achondroplasia wherein facies are normal and dwarfing is moderate to severe. Prognosis is generally good with more than $80 \%$ 
patients having normal intelligence ${ }^{11}$. Congenital heart defect is the major cause of death within the first few years of life. Timely surgical intervention and hormone therapy greatly improves the outcome.

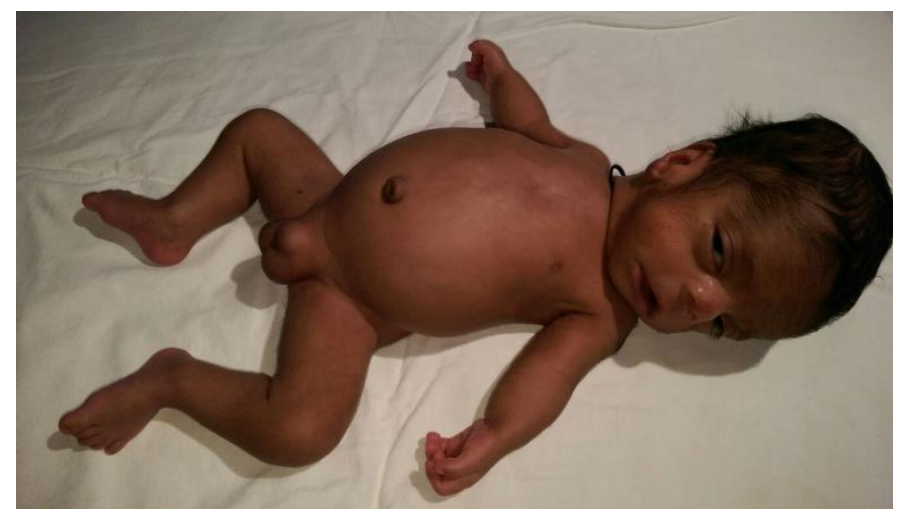

Figure 1 showing the affected newborn with characteristic fetal facies, limb shortening and genital hypoplasia

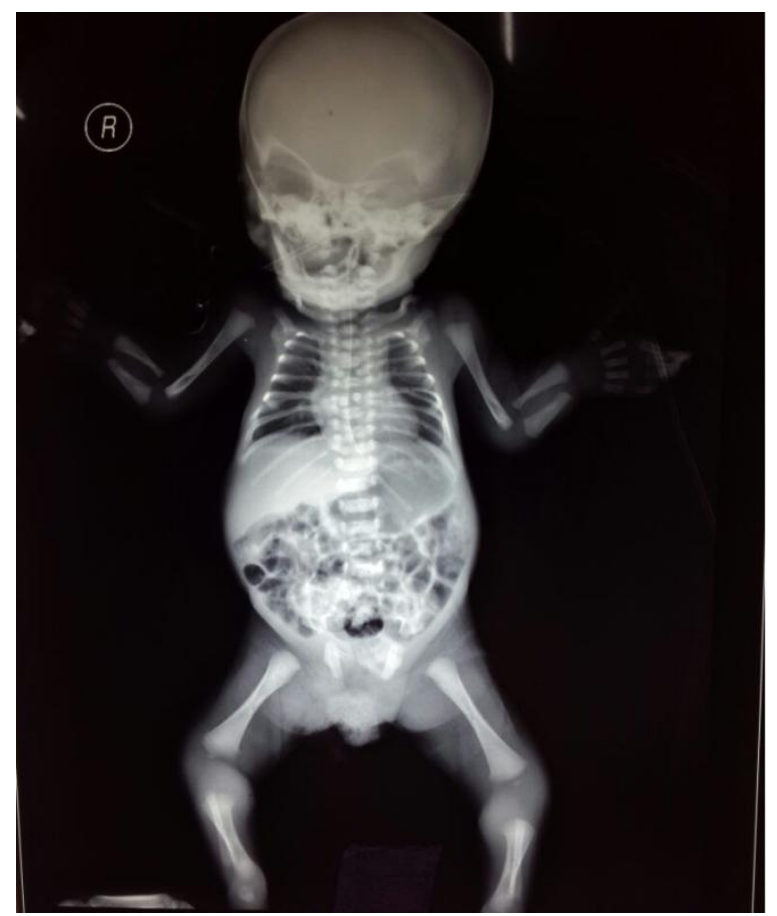

Figure 2 showing the $X$ ray of the affected baby with mesophilic shortening of bones, multiple segmentation anomalies in thoracic vertebrae and bifid fifth rib

\section{References}

1. Patton MA, Afzal AR. (2002 ) Robinow syndrome. J Med Genet 39:305-10.

2. Robinow M, Silverman FN, Smith HD. A newly recognized dwarfing syndrome. Am J Dis Child.1969 Jun;117(6):645-651.
3. Hosalkar HS, J Gerardi J, Shaw BA. (2002) Robinow syndrome. Images In Medicine: 48 (1 ) : 50-1

4. Afzal AR, Rajab A, Fenske C, Crosby A, Lahiri N, Ternes-Pereira E, Murday VA, Houlston R, Patton MA, Jeffery S. (2000) Linkage of recessive Robinow syndrome to a $4 \mathrm{cM}$ interval on chromosome 9q22. Hum Genet 106:351-4

5. Afzal AR, Rajab A, Fenske C, Oldridge M, Elanko N, Ternes-Pereira E, Tuysuz B, Murday VA, Patton MA, Wilkie AOM, Jeffery S. (2000) Autosomal recessive Robinow syndrome is allelic to dominant brachydactyly type B and caused by loss of function mutations in ROR2.Nat Genet 25:419-22.

6. Van Bokhoven H, Celli J, Kayserili H, van Beusekom E, Balci S, Brussel W, Skovby F, Kerr B, Percin EF, Akarsu N, Brunner HG.(2000) Mutation of the gene encoding the ROR2 tyrosine kinase causes autosomal recessive Robinow syndrome. Nat Genet 25:423-6. (Erratum in Nat Genet 2000;26:383.)

7. Robinow M. (1993)The Robinow (fetal face) syndrome: a continuing puzzle. Clin Dysmorphol;2:189-98.

8. https://rarediseases.org/rarediseases/robinow-syndrome/

9. Al-Ata J, Paquet M, Teebi AS. (1998) Congenital heart disease in Robinow syndrome. Am J Med Genet 77:332-3.

10. Castro S, Peraza E, Barraza A, Zapata M (2014) Prenatal diagnosis of robinow syndrome: A case report Journal of Clinical Ultrasound Jun:_42 (5) : 297-300

11. Suresh S. (2008) Robinow syndrome. Indian J Orthop. Oct;42(4):474-6. doi: 10.4103/0019-5413.43399 